\title{
EL NUEVO PARADIGMA DE LA SUSTENTABILIDAD FUERTE COMO PILAR DEL ESTADO ECOLÓGICO DE DERECHO
}

\author{
Carlos E. Peralta \\ Universidad de Costa Rica, Costa Rica. \\ carlosperalta07@gmail.com
}

\begin{abstract}
RESUMEN: La sustentabilidad ambiental fuerte constituye nuevo paradigma que objetiva un nuevo modelo de Estado de Derecho: El Estado Ecológico de Derecho. Ese modelo, fundamentado en nuevos valores, y orientado por principios de justicia ecológica, busca establecer una relación de respeto, solidaridad, prudencia y precaución entre los seres humanos y la Naturaleza, de forma que los impactos ambientales respeten los límites biofísicos. Ese nuevo modelo de Estado busca una sociedad más solidaria, pluralista, respetuosa de las diferencias y cosmovisiones y que aspire a una baja entropía y a una justicia ecológica. A partir de una perspectiva de pensamiento complejo se analizan las características, bases conceptuales y perspectivas para ese Estado Ecológico de Derecho dentro del contexto del Antropoceno
\end{abstract}

PALABRAS CLAVE: Antropoceno. Sustentabilidad ambiental fuerte. Estado Ecológico de Derecho.

The new paradigm of strong sustainability as a pilar of the environmental State of Law

ABSTRACT: Strong environmental sustainability is a new paradigm that objectives a new model of the rule of law: The ecological state of law that, based on new values, and oriented by principles of ecological justice, seeks to establish a relationship of respect, solidarity, prudence and caution between humans and nature, so that environmental impacts respect biophysical boundaries. This new model of state seeks a more supportive society, pluralist, respectful of differences and worldviews and that aspires to low entropy and ecological justice. A complex thinking perspective analyses the characteristics, conceptual bases and perspectives for that ecological state of law in the Anthropocene

KEYWORDS: Anthropocene. Strong Sustentability. Environmental State of Law.

\section{O novo paradigm da sustentabilidade forte como pilar do Estado Ecológico de Direito}

RESUMO: A sustentabilidade ambiental forte constitui novo paradigma que objetiva um novo modelo de Estado de Direito. O Estado Ecológio de Direito. Esse modelo, fundamentado em novos valores e orientado por princípios de justiça ecológica, busca estabelecer uma relação de respeito, solidariedade, prudência e precaução entre os seres humanos e a Natureza, de forma que os impactos ambientais respeitem os limites biofísicos. Esse novo modelo de Estado busca uma sociedade mais solidária, pluralista, respeitosa das diferenças e cosmovisões e que aspire a uma baixa entropia e a uma justiça ecológica. A partir de uma perspectiva de pensamento complexo se analisam as características, bases conceituais e perspectivas para esse Estado Ecológico de Direito dentro do contexto do Antropoceno.

PALAVRAS-CHAVE: Antropoceno. Sustentabilidade ambiental forte. Estado Ecológico de Direito. 


\title{
INTRODUCCIÓN
}

La complejidad ambiental es un signo marcante de la sociedad de segunda modernidad, cuya magnitud permite afirmar que el ser humano detonó una nueva era geológica: el Antropoceno. Las características de los problemas ambientales exigen que su análisis sea realizado desde una perspectiva de pensamiento complejo, que permita encontrar posibles caminos para identificar parámetros que, orientados por un criterio de sustentabilidad ambiental fuerte, direccionen las actividades humanas de forma que no se irrespeten las fronteras de riesgo ecológico.

Dentro de ese contexto, uno de los mayores desafíos de la humanidad en el siglo XXI será la formulación de un Estado de Derecho esverdeado, que, fundamentado en una sustentabilidad ambiental fuerte, valorice y respete los procesos ecológicos esenciales como requisito indispensable para la calidad de vida en la biosfera.

El presente artículo pretende realizar unas breves reflexiones sobre el fundamento, concepto, características y perspectivas para formular un Estado Ecológico de Derecho (en adelante EED) en el contexto del Antropoceno. Para realizar el análisis, el trabajo fue estructurado en tres partes: (1). En un primer momento será realizada una descripción sucinta sobre las particularidades del Antropoceno; (2) En segundo lugar, serán expuestas las premisas que permiten conceptualizar el EED; (3). La tercera parte del trabajo analizará la sustentabilidad ambiental fuerte como paradigma del EED; (4) Finalmente, la última sección se abocará al estudio de las perspectivas de ese Estado esverdeado.

\section{EL ANTROPOCENO: LA ERA DE LOS RIESGOS ECOLÓGICOS GLO- BALES}

El ser humano tiene una relación de autonomía y de dependencia con la Naturaleza; se adapta y crea las condiciones necesarias para modificar su entorno, $\mathrm{y}$, al mismo tiempo, obtiene del ambiente natural todo lo que necesita para su desarrollo. El ambienta natural es el espacio que condiciona la existencia humana y permite el ejercicio de las libertades. El ser humano no puede ser visto como ajeno a su entorno.

Al respecto, De Prada García (1998, p.20-21) explica que,

\begin{abstract}
Tan íntima es la conexión entre una y otra cosa que se difumina la distinción entre individuo y medio ambiente. Una porción del aire que respiramos se convierte en parte de nosotros. El oxígeno metaboliza nuestros alimentos y se convierte en una parte de nuestra carne y de nuestra sangre; las partículas que respiramos se acumulan en nuestros pulmones. Un porcentaje de los líquidos que bebemos pasan a formar parte nuestros cuerpos, al igual que, a su vez, se transforman en nuestros tejidos. (...) debería recordarse constantemente que, de formas muy importantes, "nosotros y nuestro medio ambiente somos uno".
\end{abstract}

A lo largo de la historia los seres humanos han provocado impactos sobre el ambiente. Sin embargo, es a partir de la Revolución Industrial que la intensidad de actividades orientadas al crecimiento económico comienzan a comprometer la capacidad de resiliencia de la Naturaleza, provocando una sobrecarga ecológica que no respeta los límites biofísicos. A partir de ese momento, los problemas ambientales, antes locales y corregibles, pasaron a alcanzar carácter global, sinérgetico, imprevisible. La relación ser humano y Naturaleza pasó a ser tensa, marcada por el utilitarismo antropocéntrico. 
Paul J. Crutzen- premio Nobel de Química- y Eugene F. Stoermer en el Boletín International Geosphere-Biosphere Programme (IGBP) afirmaron la existencia de una nueva era geológica, que substituye al Holoceno y a la que llamaron Antropoceno (2000).

Posteriormente, Paul J. Crutzen (2002), en un artículo publicado en la Revista Nature intitulado Geology of mankind-, sostuvo formalmente que el impacto de los seres humanos sobre la Terra desencadenó una nueva era geológica: el Antropoceno. Este nuevo período geológico estaría marcado por una sobrecarga ecológica causada por el modelo de desarrollo económico. La propuesta de esa nueva geológica aún no ha sido oficializada por la Unión Internacional de Ciencias Geológicas. Fue constituido el Grupo de Trabajo sobre el Antropoceno (AWG, por sus siglas en inglés $)^{1}$ para analizar las evidencias científicas sobre el Antropoceno.

Actualmente, se considera que el Antropoceno es más que un concepto geológico -sentido estricto-, alcanzando una dimensión cultural - en sentido amplio- que cuestiona el modelo de desarrollo humano y su relación con la Naturaleza. Al respecto, H. Trischler (2017, p. 54), explica que

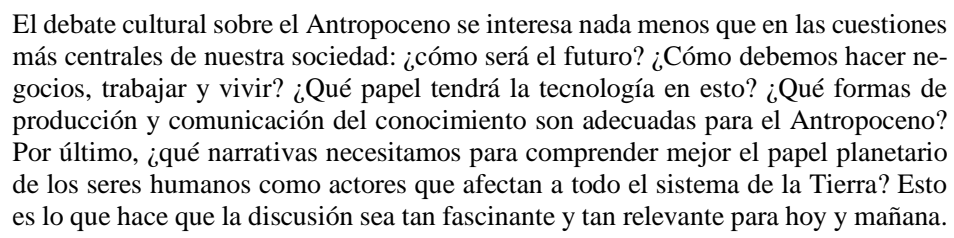

Podría afirmarse que se trata de la era del homo faber; época marcada por na sociedad de alta entropía, pautada por la idea de crecimiento económico continuo, que desconsidera que la biosfera es un sistema cerrado con fronteras de riesgo ecológico que deben ser respetadas. Por primera vez en la historia, una especie tiene el futuro de la biosfera en sus manos, pudiendo provocar una extinción de especies en masa. La racionalidad del modelo de desarrollo heredado de la conquista y de la revolución industrial no considera la vulnerabilidad y la capacidad de resiliencia de la Naturaleza, de modo que, la degradación ambiental, y los problemas que de ella se derivan son una característica y al mismo tiempo una consecuencia de esa visión de mundo.

La sobrecarga ecológica que caracteriza al Antropoceno presenta carácter sinergético, transfronterizo, y tiene una dimensión inter-geracional e inter-especies colocando el riesgo la estabilidad de la biosfera. La huella ecológica está marcando significativamente los cambios que afectan a la Naturaleza, provocando una situación tensa en la elasticidad de los ecosistemas ${ }^{2}$. Prácticamente todos los espacios naturales han sufrido significativas transformaciones en sus ciclos naturales afectando su capacidad para prestar servicios ecológicos.

De acuerdo con la Global Footprint Network, en 2019 alcanzamos el día de sobrecarga ecológica de la tierra (Overshoot day) el 29 de julio $^{3}$. De modo que, en menos de 7 meses consumimos todos los bienes y servicios que la biosfera nos puede ofrecer en un año. En otras palabras, sustentar nuestro estilo de desarrollo requiere, aproximadamente, 1,6 planetas por año.

La crisis ecológica del Antropoceno desencadenará la pérdida masiva de especies, detonó y agrava el cambio climático, ocasiona problemas hídricos -falta de acceso a agua, mala calidad del agua-, genera conflictos socio-ambientales, migraciones masivas, hambre, enfermedades, ca-

\footnotetext{
Al respecto consultar Anthropocene Working Group (2019)

Sobre el concepto de huella ecológica consultar Romero, 2003.

3 Cf. Global Footprint Network en https://www.footprintnetwork.org/2019/06/26/press-release-june-2019-earthovershoot-day/
} 
tástrofes naturales, etc. De manera que, tenemos un alto grado de autonomía con un mundo altamente tecnológico e interconectado, pero al mismo tiempo estamos colocando en jaque la estabilidad de la biosfera que nos dio esa autonomía. La racionalidad del modelo que tiene el crecimiento económico como pilar del desarrollo no integró la vulnerabilidad y la capacidad de resiliencia de la Naturaleza.

El Antropoceno está marcado por una serie de características que se encuentran en un círculo de causa y consecuencia las unas con las otras.

(1) Aumento demográfico exponencial. En el año de 1800 había 1 billón de personas sobre la Tierra, hoy hay aproximadamente 7 billones. Para el 2050 se espera que la población mundial sea de 9 billones de personas.

(2) Modificación de los espacios naturales: Urbanización y expansión agropecuaria. El Antropoceno es una época caracteriza por la construcción del ambiente artificial. Se espera que para el 2050, 70\% de la población viva en áreas urbanas.

Por su parte, la expansión de las actividades agropecuarias ha provocado deforestación y destrucción de habitas naturales.

(3) Sociedad de alta entropía, altamente dependiente de combustibles fósiles. El modelo de desarrollo imperante exige una gran cantidad de energía para poder funcionar.

(4) Cultura de lo superfluo. El “ciclo extracción-producción-consumo-desechos" está pautado por una lógica de lo efímero, cuyo diseño responde a una economía de materiales de naturaleza lineal, fundamentada en la idea de una "obsolescencia programada $y$ deseada”. El rápido flujo de mercaderías y servicios promovido por el sistema económico tiende a agotar los recursos renovables, a degradar los renovables y a devolver calor, contaminación y residuos al ambiente.

A pesar de lo indicado, cabe resaltar que al tiempo que se produce una enorme afluencia, existe una profunda desigualdad.

(5) Inducción Contra-Natura. La sociedad que desencadenó el Antropoceno está conformada por un conjunto de instituciones, normas y actores que desconsidera los costos socioambientales en sus decisiones económicas.

Las diversas decisiones de los agentes económicos, desde la extracción, hasta el momento de desechar, se encuadran dentro de una estructura económica, política, y social que desconsidera el ambiente como factor clave. Existen señales, normas, que orientan a los diversos agentes a tomar decisiones que no se preocupan con internalizar los impactos en el ambiente. En otras palabras, los procesos que caracterizan la idea de desarrollo no incorporan los costos socio-ambientales. El modelo está pautado por una irresponsabilidad organizada, caracterizada por un marco jurídico-político disperso, incoherente, que desconsidera las evidencias técnico científicas y que promueve un desarrollo (in)sostenible.

El Estado de Derecho del siglo XX, e inicios del siglo XXI, es un Estado que fue diseñado para estimular la producción sin limitaciones de carácter ambiental.

(6) Los riesgos ambientales originados en el Antropoceno tienen un carácter global, transfronterizo, sinergético, son discriminantes y al mismo tiempo tienen lo que U. Beck (2002) llama efecto "boomerang; es decir, pese a tener una mayor intensidad sobre ciertos grupos más vulnerables - de países o de individuos-, tarde o temprano todos sufrirán las consecuencias de los daños ecológicos. Los conflictos ecológicos exigen una nueva concepción de justicia tanto sustantiva como procedimental. 
(7) La preocupación por la tutela jurídica del ambiente es un fenómeno reciente, que se origina a partir de la Declaración de Estocolmo en la década de los setenta. Esa protección ha tendido desde entonces un carácter marcadamente antropocentrista. Recientemente se inicia el debate por introducir la discusión sobre nuevos paradigmas de protección del ambiente. Inclusive, no en pocas latitudes, la tutela del ambiente es realizada a partir del derecho administrativo, civil o penal, desconociendo las particularidades propias de la epistemología jurídico ambiental.

Actualmente, no existe aún un modelo procedimental ambiental consolidado, lo que puede reflejarse, por ejemplo, en la falta de tribunales ambientales o de una hermenéutica jurídico-ambiental consolidada en los tribunales existentes.

(8) No hay un modelo de gobernanza internacional que sea capaz de dar respuesta a la complejidad ambiental y establecer normas globales ambientales con capacidad de enforcement.

De modo que, la crisis ambiental es una característica central del modelo de desarrollo económico de la sociedad de la segunda modernidad. Ese modelo ha desencadenado una difusión de riesgos ambientales de dimensión global colocando en jaque la existencia y la calidad de vida sobre la biosfera.

Las características del Antropoceno han provocado en los ecosistemas cambios sin precedentes en la historia de la humanidad. Prácticamente todos los ecosistemas han sufrido una transformación significativa en sus ciclos naturales, afectando la capacidad de regenerarse y prestar servicios ecosistémicos.

El Antropoceno ha generado problemas complejos, todos conectados y de consecuencias imprevisibles. Esos problemas comprometen la calidad de vida tal y como la conocemos. Entre algunos de ellos podemos citar: (1). El Cambio Climático; (2). La Sobre explotación y la pérdida de biodiversidad; (3). La Erosión del suelo; (4). La Transformación de los suelos en tierras para cultivo; (5). El comprometimiento de la seguridad alimentaria comprometida por agrotóxicos, transgénicos, entre otros; (6). La Escasez de agua y la inadecuada gestión de recursos hídricos; (7). Los problemas oriundos de la disposición de residuos; (8). La pérdida de áreas de manglar y arrecifes de coral, entre otros.

En resumen, el Antropoceno es una época en la cual la sociedad creció, se urbanizó, fundamento el desarrollo humano en la idea de crecimiento, y está transformando y destruyendo la biosfera.

\section{Premisas para una APROXimación al CONCEPTO de eStado ECOLÓGICO DE DERECHO.}

En abril del 2016 se realizó, en la ciudad de Rio de Janeiro, el Primer Congreso Mundial de Derecho Ambiental de la UICN, evento en el cual se adoptó la denominada "Declaración Mundial acerca del Estado de Derecho en materia ambiental". En ese documento se alertó que "la inexistencia de un Estado ecológico y la falta de cumplimiento de los derechos y las obligaciones de índole legal, podrían tornar arbitrarias, subjetivas e impredecibles la buena gobernanza, la conservación y la protección ambiental" (UICN, 2016)

Las características de la complejidad ambiental del Antropoceno exigen un nuevo modelo de Estado de Derecho: El Estado Ecológico. Ese modelo, fundamentado en nuevos valores, deberá, a partir de una perspectiva de pensamiento complejo, establecer una relación de respeto, 
solidaridad, prudencia y precaución del ser humano para con la Naturaleza. El EED deberá propugnar una sociedad más solidaria, y de baja entropía guiada por un principio de sustentabilidad ambiental fuerte.

El Profesor de la Universidade Federal de Santa Catarina (UFSC), José Rubens Morato Leite (2008) explica que el Estado Ecológico constituye un concepto de cuño teórico abstracto que comprende elementos jurídicos, sociales y políticos que busca una condición ambiental capaz de favorecer la armonía entre los ecosistemas, y, consecuentemente, garantizar la plena satisfacción de la dignidad en sentido amplio, más allá de su concepción humana.

La crisis ambiental de la segunda modernidad trae consigo la exigencia de reconocer una nueva dimensión de los derechos fundamentales, imponiendo al Estado de Derecho el desafío de incorporar dentro de sus principales obligaciones la defensa de la Naturaleza de acuerdo a criterios de sustentabilidad que consideren los límites biofísicos de la biosfera

El EED es un proyecto jurídico-político que incorpora nuevos valores, reconoce el derecho-deber fundamental de protección/defensa ambiental, objetivando una nueva estructura de gobernanza que incorpore una racionalidad capaz de gestionar y dar respuestas adecuadas a la complejidad ambiental que caracteriza a la sociedad de riesgo propia del Antropoceno.

El EED se configura como nuevo paradigma del siglo XXI, postulando una transformación radical del orden jurídico, económico, político y social. El desafío en el plano jurídico es poder conciliar antropocentrismo y ecologismo permitiendo una relación responsable y solidaria del ser humano para con la Naturaleza, reconociendo su valor intrínseco y su relevancia para el desarrollo de las libertades humanas. A partir de ese nuevo paradigma, se debe reconsiderar el concepto de propiedad, bienes libres, ciudad, técnica, cultura, producción, consumo, gobernanza, etc.

Ese nuevo modelo solo será posible a través del esverdeamiento del Derecho, como instrumento orientado por el principio de sustentabilidad capaz de incentivar una ciudadanía ecológica responsable. El EED es un modelo de Estado reformulado, actualizado de acuerdo con una realidad compleja y cambiante que exige la incorporación de una epistemología jurídica ecológica y de una hermenéutica ambiental que permitan que el derecho sea capaz de entender la complejidad de los problemas ambientales posibilitando la resolución equitativa y oportuna de los conflictos que de ellos se deriven.

Esa versión esverdeada del Estado permitirá proteger de manera efectiva los derechos individuales y sociales, incorporando la tutela de los derechos difusos, transindividuales, sin que exista ningún tipo de superposición entre las dimensiones de derechos (LEITE; CAETANO, 2012). Ese Estado esverdeado parte del presupuesto de que los derechos de primera y segunda dimensión solo son posibles de ejercerse en un ambiente equilibrado, saludable y resiliente.

El esverdeamiento del Derecho deberá pautarse por una serie de principios derivados de una concepción de sustentabilidad ambiental fuerte y pautados por una perspectiva de pensamiento complejo, de carácter pluralista: (1). Principios de Progresividad y No Regresión; (2). Principios de Prevención y de Precaución; (3). Principios de Equidad Intra e Intergeneracional; (4). Principio de Equidad Interespecies; (5). Principios Procedimentales ambientales -participación, información y acceso a la justicia; (6). Principios del Causante, Quien Contamina Paga, Protector-recibidor, usuario-recibidor; (7). Principio de respeto por el valor intrínseco de la Naturaleza y responsabilidad con los procesos ecológicos esenciales; (8). Principio de Subsidariedad; (9). Principio de cooperación internacional en la protección del medio ambiente; (10) Principio de responsabilidades comunes pero diferenciadas de los Estados en la preservación ambiental. 
Las características que marcan la crisis ecológica del Antropoceno exigen una racionalidad que incorpore la variable ecológica en los diversos procesos de decisión -individual, local, nacional, global-. Esa racionalidad deberá estar fundamentada por un pensamiento inclusivo y holístico capaz de respetar las cosmovisiones y filosofías de vida. Se trata de la introducción de nuevas epistemologias, basadas en una ética del respeto por el "otro", y en la idea de responsabilidad con la Naturaleza y, consecuentemente, con la dinámica de sus procesos ecológicos. Esa perspectiva, evidentemente deberá tener a la educación como campo privilegiado para la transformación civilizatoria que exige la construcción de una sustentabilidad en sentido fuerte, y además deberá estar fundamentada en una política de la diversidad y de la diferencia. Dentro de esa perspectiva, la Naturaleza no debe ser vista apenas como un recurso con valor económico incorporado, que está en función del desarrollo de los seres humanos, un simple costo del crecimiento económico.

De acuerdo con Leff (2006, p. 133-134), la sustentabilidad ecológica aparece como un criterio normativo para reconstruir el orden económico; problematiza y cuestiona las formas de conocimiento, los valores sociales y las propias bases de producción. Dentro de esa perspectiva, los límites biofísicos que permiten el equilibrio ecológico serán las pautas para el desarrollo humano.

\section{LA SUSTANTABILIDAD FUERTE COMO PRINCIPIO ORIENTADOR DEL ESTADO ECOLÓGICO DE DERECHO}

La noción hegemónica de desarrollo sostenible adopta una perspectiva que puede ser conceptualizada como débil, fundamentada en tres pilares básicos, y, en teoría, de igual peso: economía, sociedad y recursos naturales.

Según esa perspectiva, en principio, esos tres pilares deberán coexistir como equivalentes, y ser valorados de igual forma en caso de conflicto. Sin embargo, en la práctica, el modelo de desarrollo vigente, pautado por la idea de crecimiento económico como sinónimo de bien estar se aleja de esa concepción teórica. En general, los intereses económicos tienen mayor peso a la hora de realizar el ejercicio de ponderación. Ello es una consecuencia lógica de un modelo que internaliza la lógica ambiental en la económica desconsiderando los límites biofísicos de la biosfera y los criterios de justicia socio-ecológica.

Para el autor alemán Gerd Winter (2009, p.7), la perspectiva débil, adoptada por el tradicional concepto de desarrollo sostenible, hace un juicio no adecuado sobre la amplitud del peso de la naturaleza, adoptando un concepto que propaga la equivalencia de los tres pilares, conduciendo a huir del trabajo conceptual de atribuir a la naturaleza el peso adecuado, lo que provoca el agotamiento el agotamiento de los recursos naturales y el desequilibrio ecológico.

La complejidad ambiental del Antropoceno exige lo que Winter llama de sustentabilidad fuerte en la cual

\footnotetext{
[...] a biosfera torna-se de "fundamental" importância. A economia e a sociedade são parceiros mais fracos, pois a biosfera pode existir sem os humanos, mas os humanos certamente não podem existir sem a biosfera. Portanto, humanos, enquanto exploram a natureza, devem respeitar suas limitações, uma necessidade que eles são capazes de preencher, uma vez que possuem o potencial da razão e então, os padrões alternativos de ponderação do comportamento (2009, p. 4).
}

El núcleo básico de esa perspectiva es el respeto por la resiliencia y los límites biofísicos naturales, entendiendo la relevancia de la continuidad de los servicios ecosistémicos como fuente 
El nuevo paradigma de la sustentabilidad fuerte como pilar del estado ecológico de derecho

indispensable para la vida, y para el desarrollo pleno de los seres humanos - desde una perspectiva intra e intergeneracional.

El objetivo de ese nuevo paradigma consiste en alcanzar un estado de prosperidad, caracterizado por un equilibrio duradero y equitativo que respete los límites intrínsecos de la naturaleza. Así, el desarrollo no deberá ser visto como sinónimo de crecimiento económico, sino que deberá considerar aspectos de justicia ecológica.

Al respecto, Clóvis Cavalcanti (2003, p. 161) explica que: “A busca da sustentabilidade resume-se à questão de se atingir harmonia entre seres humanos e a natureza, ou de se conseguir uma sintonia com o 'relógio da natureza' (...)"

La nueva racionalidad ecológica deberá partir de que los fenómenos naturales no pueden ser reducidos a la lógica del mercado, por el contrario son los procesos de transumo los que deben adaptarse y respetar los límites biofísicos. Se debe entender que la economía es apenas un subsistema dentro de la biosfera, y, consecuentemente deberá respetar las zonas de riesgo ecológico.

De la dinámica de la Naturaleza deben ser extraídos parámetros que permitan orientar la transición de una sociedad fundamentada en una economía marrón, lineal y utilitarista para una sociedad con una economía esverdeada, circular, solidaria, equitativa y capaz de reconocer el valor intrínseco de la Naturales. Siguiendo a Miller (2008, p. 136), es posible afirmar que los nuevos parámetros deberán partir de que:

(1) Todo en la Naturaleza es interdependiente. Cualquier intervención antropogênica en el ambiente tenderá efectos colaterales inesperados. Por ello, las evaluaciones de riesgo e impacto ambiental, fundamentadas en criterios técnico científicos y amparadas en los principios de prevención y precaución, son imprescindibles. Evidentemente, la independencia funcional y económica de las agencias que realicen esas evaluaciones es requisito sine qua non, para evitar presiones políticas o económicas. Además, dentro de ese marco, los principios procedimentales ambientales -información, participación y acceso a la justicia- son fundamentales dentro de una democracia ambiental. La prudencia ecológica, base de la pirámide de una sustentabilidad fuerte deberá orientar y limitar proyectos que impacten significativamente a la Naturaleza.

(2) La naturaleza funciona, esencialmente, a base de energía solar: La matriz energética de una sociedad que aspire a funcionar con baja entropía deberá depender de energía renovable. Es necesario establecer un marco de incentivos económicos para el desarrollo de tecnologías limpias, $\mathrm{y}$, al mismo tiempo, desincentivos para energías de impacto negativo, eliminando, además, cualquier subsidio que sea contrario a los principios de la sustentabilidad fuerte.

(3) La naturaleza recicla nutrientes y residuos: El EED deberá prevenir y reducir la contaminación, promover el consumo ecológico consiente -Rechazo, reaprovechamiento y reciclaje- desestimulando estrategias de obsolescencia programada.

En palavras de Daly (2005, p. 96) "Uma economia sustentável requer uma 'transição demográfica' não apenas de pessoas, mas também de bens - as taxas de produção deveriam ser iguais às taxas de depreciação, em níveis elevados ou baixos”.

(4). La naturaleza preserva la biodiversidad y los servicios ecositémicos: No es posible sustentar de forma indefinida una sociedad que degrada el ambiente. Debe repensarse la forma de interacción con la Naturaleza, promoviendo una sociedad de baja entropía que respete los 
límites biológicos aplicando criterios de sustentabilidad y justicia distributiva. Es necesaria la amalgama de nuevos paradigmas que contemplen una perspectiva biocentrica.

(5). La Naturaleza controla el tamaño poblacional y el uso de los recursos: Debe evitarse el desperdicio, y promover la distribución equitativa del espacio natural y de los recursos naturales.

Esos parámetros, extraídos del funcionamiento de la Naturaleza, deben ir acompañados de una Ecoética que oriente una ciudadanía ecológica solidaria y responsable con el otro. Leite e Ayala explican que esa ciudadanía deberá ser ejercida en términos planetarios y transfronteirzos. Esa necesidad se justifica no solo apenas por la integralidad del ambiente y de los intereses relacionados, como también por la globalidad de la crisis ambiental (LEITE; AYALA, 2004).

La ciudadanía ecológica deberá estar fundamentada en una nueva educación, que deberá partir de la premisa que el ser humano debe tener una relación de respeto y armonía con la Naturaleza. Esa ciudadanía deberá estar direccionada por la idea de responsabilidad y solidaridad para con un otro normalmente invisivilizado en el actual modelo de desarrollo - las otras especies que habitan el planeta y las futuras generaciones-

Dentro de ese contexto de transición para una sociedad sustentable, el Estado contemporáneo deberá desempeñar un relevante papel en la adopción de políticas públicas que promuevan la ciudadanía ecológica y orienten actividades y conductas sustentables.

Como afirma Morato Leite (2003), la crisis ambiental torna cada vez más aparente la necesidad de reformular los pilares que sirven de base para el Estado, lo que presupone, inevitablemente, la adaptación de un modelo de desarrollo apto para considerar a las futuras generaciones y el establecimiento de una política fundamentada en el uso sustentable de la Naturaleza. Como afirma Daly (2005, p. 92) "Desenvolver uma economia sustentável em uma biosfera finita exige novas maneiras de pensar". Así, una nueva racionalidad ecológica deberá imponer una reformulación radical del concepto de desarrollo vigente, exigiendo repensar su teoría, instituciones, el modo de utilizar los recursos naturales, el cuestionamiento del trasumo/consumismo, y la forma de eliminar residuos.

En síntesis, una pirámide de la sustentabilidad ambiental fuerte tiene, en su base, un parámetro precautorio, amparado en el conocimiento científico más adecuado que deberá considerar la capacidad de resiliencia de la Naturaleza de forma que sean respetados sus límites biofísicos. Se trata del pilar inicial, que deberá determinar si, en un segundo momento es posible realizar un análisis de ponderación en el cual sean considerados 5 elementos: Ecológicos (evaluación de posibles impactos), sociales, económicos, políticos, geográficos y tecnológicos. La imagen 1, refleja esa nueva concepción de sustentabilidad. 


\section{Imagen 1. Sustentabilidad fuerte}

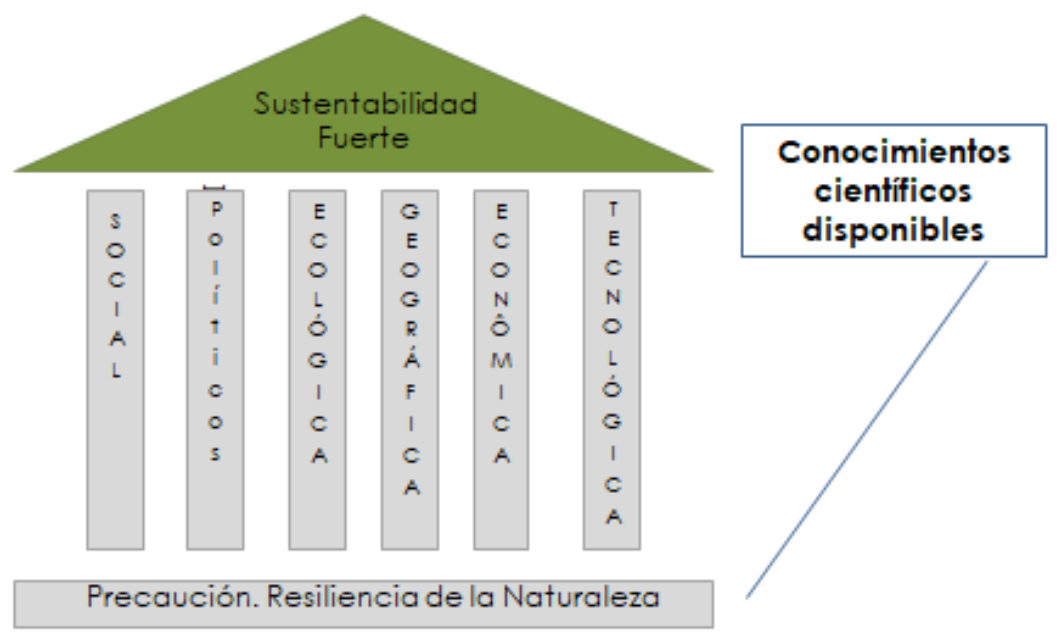

Fuente: Elaboración propia (2019)

\section{Perspectivas del Estado Ecológico de Derecho}

La Declaración Mundial adoptada por la UICN en abril del 2016, sobre el Estado de Derecho en materia ambiental ${ }^{4}$, es un insumo relevante para identificar los principios que permiten nortear el esverdeamiento del Estado de Derecho. Ese documento expresamente destaca que "la humanidad coexiste con la naturaleza y que toda forma de vida depende de la integridad de la biosfera y de la interdependencia de los sistemas ecológicos”.

La Declaración de la UICN/2016, en su apartado segundo (II) reconoce 13 principios generales y emergentes- que deberán nortear el EED. En síntesis, dichos principios son orientaciones sustentables que determinan:

1. El reconocimiento intrínseco del valor de la Naturaleza, más allá de cualquier fin utilitarista. Ese reconocimiento exige el deber de todos -Estado, entidades, ciudadanos- de proteger la Naturaleza, respetando sus límites biofísicos, su capacidad de resiliencia y la evolución de los procesos ecológicos;

2. El derecho humano al ambiente ecológicamente equilibrado, con una dimensión intrageneracional e intergeneracional;

3. La consolidación de un derecho ambiental con una responsabilidad prospectiva capaz de adoptar normas de protección y restauración que permitan mantener y mejorar la resiliencia de los ecosistemas. Se resalta la función ecológica de la propiedad;

4. La aplicación del Principio In Dubio Pro Natura, en los diversos procesos de decisión, cuando exista duda sobre el riesgo o peligro ambiental;

4 Declaración disponible en https://www.iucn.org/sites/dev/files/content/documents/spanish_declaracion_mundial_de_la_uicn_acerca_del_estado_de_derecho_en_materia_ambiental_final.pdf 
5. El carácter integrador, pluralista, multicultural y holístico del $E E D$, debiendo promover la igualdad de género, la participación de grupos minoritarios y vulnerables, y el reconocimiento de los derechos de los pueblos indígenas y tribales;

6. La importancia de los principios de no regresión y de progresividad, para garantizar y mejorar las normas jurídicas ambientales y el acceso a la justicia, con el apoyo de los conocimientos científicos más recientes.

De los principios de la citada declaración es posible afirmar que el Estado Ecológico de Derecho es una exigencia que deviene de los riesgos ambientales que caracterizan el Antropoceno y constituye un requisito indispensable para poder orientar una justicia ecológica integral -intrageneracional, intergeneracional e interespecies, capaz de proponer un modelo de gobernanza más equitativo. Ese modelo busca establecer una responsabilidad organizada con parámetros eco-éticos que delimiten un marco sustantivo y procedimental con una pretensión real de efectividad.

El EED deberá tener como fundamento la idea de una sustentabilidad fuerte, que, teniendo como base el equilibrio ecológico, elabore e implemente normas con parámetros claros, amprados en conocimiento científico, orientadas al uso equitativo y racional de la Naturaleza, respetando su valor intrínseco y sus límites biofísicos.

Una nueva racionalidad ambiental implica la legitimación de nuevos valores, de nuevos derechos y de nuevos criterios para tomar decisiones democráticas que permitan nuevas políticas ambientales. El desafío de una sustentabilidad ambiental fuerte es cuestionar la realidad predominante que fue edificada con base en una racionalidad que no incorporó los límites biofísicos como presupuesto base que debe ser respetado por el modelo de desarrollo humano.

Los riesgos ambientales que caracterizan el Antropoceno exigen un nuevo modelo de Estado, el cual, como explica Fensteiseifer (2008), deberá incorporar, a las conquistas positivas logradas en términos de tutela de la dignidad humana, la tutela efectiva de derechos tran-sindividuales. En un paradigma de solidaridad (en su dimensión local, nacional, regional e internacional), el Estado deberá proyectarse en una dimensión ecológica que objetive la efectividad de los derechos de la sustentabilidad, promoviendo el debate de nuevos paradigmas que garanticen el respeto de los límites biofísicos de la Naturaleza, la salud y la vida en sentido amplio. Así, los derechos de la sustentabilidad se convierten en parámetros, requisitos sine qua non, para el ejercicio de los derechos fundamentales de los seres humanos.

La complejidad ecológica del Antropoceno impone al EED el desafío de incorporar la sustentabilidad como parámetro fundamental para un nuevo modelo de desarrollo. Entre los principales desafíos de ese proyecto de $E E D$ podemos enumerar:

(1) Invertir en educación verde, reconociendo el valor intrínseco da Naturaleza. Nuevos paradigmas ecológicos son objeto de debate, reconociéndose, tanto a nivel jurisprudencial como legislativo, a la Naturaleza y a los animales como sujetos de derechos;

(2) Combatir la corrupción y fortalecer los sistemas de fiscalización y evaluación ambiental;

(3) Incentivar nuevas tecnologías que permitan migrar de una economía marrón para una economía verde (desmaterializada);

(4) El Reconocimiento y fortalecimiento de los derechos de la sustentabilidad como derechos humanos: Mínimo existencial ecológico, derecho a un clima estable, derecho al agua y saneamiento básico, derecho a la información y participación en materia ambiental, derecho de acceso a la justicia para resolución de conflictos ecológicos; 
El nuevo paradigma de la sustentabilidad fuerte como pilar del estado ecológico de derecho

(5) Repensar los modelos de gobernanza y gobernabilidad para permitir una mayor efectividad de las normas ambientales

Dentro de esa línea de acciones, es evidente que el Derecho, a partir de una perspectiva de pensamiento complejo, deberá revisar sus esquemas conceptuales tradicionales para ser capaz de reestructurar el proceso de incentivos que conduce a los seres humanos a degradar el ambiente. La complejidad ambiental exige que el derecho se apoye en el conocimiento científico, adoptando una visión prospectiva, con un carácter más preventivo que represivo.

Siguiendo el pensamiento de José Eli da Veiga (2012, p.18), consideramos que deberá ser realizado un cambio radical en las políticas tributarias, permitiendo una Reforma fiscal verde, fundamentada en la Teoría del doble dividendo, que permita modificar la carga fiscal estructurada de acuerdo con una economía marrón - que tributa el trabajo y el capital -, para una tributación extrafiscal que incentiva actividades ecológicamente correctas y aumenta la carga fiscal de bienes y servicios con mayor impacto sobre la Naturaleza (PERALTA, 2014).

Sobre el tema, Daly (2005, p. 97) afirma que,

Um governo preocupado com o uso mais eficiente de recursos naturais mudaria o
alvo de seus impostos. Em vez de taxar a renda auferida por trabalhadores e empresas
(o valor adicionado), tributaria o fluxo produtivo (aquele ao qual é adicionado valor),
de preferência no ponto em que os recursos são apropriados da biosfera, o ponto de
"extração" da Natureza.

Por otra parte, es relevante el fortalecimiento de la Gobernabilidad Ecológica, en los diversos niveles (local nacional, regional, global). Ese proceso deberá estar acompañado del protagonismo de la sociedad civil en la toma de decisiones de relevancia ambiental. A partir del fenómeno participación democrática y ciudadana en la defensa del ambiente, se desprenden cuatro sub-principios: (1)- El principio de participación popular; (2). El principio de acceso a la información ambiental; (3). El principio de Educación Ambiental; (4). El principio de consumo sustentable (Fenstenseifer, 2008)

A nivel nacional, advirtiendo que no existen modelos estandarizados, conviene enumerar 5 recomendaciones para una adecuada Gobernabilidad Ecológica:

(1) Fortalecer la gestión descentralizadora, transfiriendo competencias para la tomada de decisiones a gobiernos locales y a comunidades tradicionales;

(2) Integrar programas de sustentabilidad dentro de las estrategias de desarrollo y reducción de pobreza a nivel nacional, regional y local;

(3) Implementar estrategias de prevención y reducción de riesgos de desastres. El ordenamiento territorial es esencial como ejercicio de planificación en regiones y ciudades;

(4) Fortalecer los procesos de negociación multi-actores, estimulando la cooperación y captación de recursos para el desarrollo local sustentable;

(5) Asegurar la compatibilidad entre a legislación ambiental y la institucionalidad, combatiendo la corrupción.

En al ámbito internacional, los organismos de gobernabilidad ambiental, incluidos dentro de estructuras formuladas en la primera mitad del siglo XX, están anclados en una visión heredada de la primera modernidad -simple, lineal, industrial-, fundamentada en la sociedad de Estados Naciones. Existen programas y foros poco articulados, procesos de decisión obsoletos, y acuerdos globales sin financiamiento o capacidad de enforcement. 
La complejidad ambiental del Antropoceno exige una nueva arquitectura institucional ambiental global, sólida y eficaz capaz de entender que el mundo actual es más que la simple suma de países. Esa nuevo modelo de gobernabilidad internacional deberá contar con capacidad de articulación, recursos financieros estables, poder normativo y capacidad de enforcement. Considerando la complejidad ambiental, algunas acciones concretas podrían orientar el debate sobre un nuevo modelo de Gobernabilidad Ambiental Internacional:

(1) Aplicar el principio de subsidiariedad. Pensar global, actuación local;

(2) Promover la cooperación regional para articular y coordinar acciones conjuntas entre países, con el objetivo de contribuir con soluciones científico-tecnológicas propias a los problemas del desarrollo de cada región. Sería interesante discutir la posibilidad de organizar foros multi-atores, y constituir conjuntos geopolíticos regionales o bloques de países con intereses comunes;

(3) Discutir si la reformulación de los organismos existentes en la ONU sería suficiente para permitir una gobernabilidad ambiental eficaz. Deberá evaluarse la necesidad de crear un organismo más independiente, encargado específicamente de temas de sustentabilidad ambiental, o si sería más conveniente redefinir las reglas y criterios de la Organización Mundial del Comercio (OMC), y crear, por ejemplo, una Organización Mundial de la Sustentabilidad. Independientemente de la arquitectura institucional adoptada, es fundamental establecer fuentes de financiamiento estables;

(4) Es fundamental discutir y adoptar indicadores de sustentabilidad ambiental globales, que consideren las particularidades regionales;

(5) Crear un Tribunal Internacional Ambiental capaz de sancionar Estados y empresas nacionales y transnacionales.

\section{CONCLUSIÓN}

Los problemas y riesgos ecológicos son un signo marcante del Antropoceno. Su solución requiere un diálogo de saberes, transdisciplinario, pluralista, que sea capaz de adoptar criterios de responsabilidad ecológica que respeten las fronteras de riesgo ecológico identificadas por el conocimiento científico.

Conforme expuesto, la complejidad ambiental del Antropoceno exige repensar el modelo de desarrollo hegemónico fundamentado en la idea de crecimiento económico. La sustentabilidad ambiental fuerte como nuevo paradigma permite conceptualizar las perspectivas para configurar un Estado Ecológico de Derecho con una racionalidad que respete los límites biofísicos del planeta y sea capaz de dar respuesta a los riesgos ecológicos. Así, ese nuevo paradigma deberá tener como objetivo alcanzar un estado de prosperidad, caracterizado por un equilibrio duradero y equitativo, en el cual la idea de desarrollo no esté limitada a aspectos relacionados con crecimiento económico.

La Declaración de la UICN sobre el Estado de Derecho en materia ambiental se constituye como una relevante iniciativa que permite orientar caminos para alcanzar la sustentabilidad ambiental fuerte. De ese documento es posible concluir que el EED deberá, por un lado, conciliar los derechos liberales, sociales con los derechos ecológicos, promoviendo el reconocimiento de los derechos de la naturaleza y la justicia ecológica en un mismo proyecto jurídico político para la comunidad estatal. Ese modelo deberá objetivar una ciudadanía ecológica cosmopolita capaz de entender a la Naturaleza por su valor intrínseco. 
El EED deberá contribuir de forma responsable y activa para estructurar un modelo de gobernabilidad ambiental internacional dinámico, cooperativo, informado, transparente y con capacidad de enforcment.

La complejidad ambiental se constituye en el gran reto del siglo XXI, exigiendo nuevas epistemologías capaces de lidiar con la imprevisibilidad de los riesgos ambientales existentes. Para ello, hay una exigencia de un nuevo modelo de Estado y de una gobernabilidad ambiental global pautada por un principio de sustentabilidad que exige la contención del ser humano y la prudencia en su relación con el ambiente.

\section{REFERENCIAS}

ANTHROPOCENE WORKING GROUP. Working group on the 'Anthropocene'. 2019. Disponible en: http://quaternary.stratigraphy.org/working-groups/anthropocene/. Acceso en 30 ago. 2019.

BECK, Ulrich. La sociedad del riesgo global. Madrid: Siglo Veintiuno, 2002.

CAVALCANTI, Clóvis. Sustentabilidade da economia: paradigmas alternativos de realização econômica. In: CAVALCANTI, Clóvis (org.). Desenvolvimento e natureza. Estudos para uma sociedade sustentável. São Paulo. Cortez, 2003.

CRUTZEN, P.J. Geology of mankind. Nature, v. 415, 2002. Disponible en: http://nature.berkeley.edu/classes/espm-121/anthropocene.pdf. Acceso en: 20 ago. 2019.

CRUTZEN, Paul J.; STOERMER, Eugene F. The Anthropocene. Global Change Newsletter. núm. 41, Disponible en: http://www.igbp.net/download/18.316f18321323470177580001401/ 1376383088452/NL41.pdf. Acceso en: 20 de agosto de 2019.

DALY, Herman. Sustentabilidade em um mundo lotado. Scientific American Brasil. Edição Especial. São Paulo, ano 4, n. 41, 2005.

DE PRADA GARCÍA, Aurelio. Justicia y protección fiscal del medio ambiente. In: YABAR STERLING, Ana (ed.) Fiscalidad ambiental. Barcelona: Cedecs, 1998.

FENSTERSEIFER, Tiago. Direitos Fundamentais e proteção do ambiente. A dimensão ecológica da dignidade humana no marco jurídico-constitucional do Estado Socioambiental de Direito. Porto Alegre: Livraria do Advogado editora, 2008.

LEFF, Enrique. Racionalidade Ambiental: a reapropriação social da natureza. Tradução: Luís Carlos Cabral. Rio de Janeiro: Civilização Brasileira, 2006.

LEITE, José Rubens Morato; CAETANO, Matheus Almeida. Breves Reflexões sobre os Elementos do Estado de Direito Ambiental Brasileiro. In: LEITE, José Rubens Morato; FERREIRA, Heline Sivini; CAETANO, Matheus Almeida. Repensando o Estado de Direito Ambiental. Florianópolis: Fundação Boiteux, 2012.

LEITE, José Rubens Morato. Sociedade de risco e Estado. In: CANOTILHO, José Joaquim Gomes; LEITE, José Rubens Morato. (organizadores). Direito constitucional ambiental brasileiro. 2.ed. São Paulo: Saraiva, 2008.

LEITE, José Rubens Morato. Dano ambiental: do individual ao coletivo extrapatrimonial. 2. ed. São Paulo: Revista dos Tribunais, 2003. 
MILLER JR., G. Tyler. Ciência ambiental. Tradução da 11. edição norte-americana. Tradução de All Tasks. $1^{\text {a }}$ reimpressão. São Paulo: Cengage Learning, 2008.

MONTERO, CARLOS EDUARDO PERALTA. Tributação Ambiental: reflexões sobre a introdução da variável ambiental no sistema tributário. São Paulo: Saraiva, 2014.

ROMEIRO, Ademar Ribeiro. Economia ou Economia Política da Sustentabilidade. In: MAY, Peter H.; LUSTOSA, Maria Cecília; VINHA, Valeria da. (organizadores). Economia do meio ambiente: teoria e prática. Rio de Janeiro: Elsevier, 2003

TRISCHLER, H. El Antropoceno ¿un concepto geológico o cultural, o ambos? Desacatos 54, 2017. Disponible en: http://www.scielo.org.mx/pdf/desacatos/n54/2448-5144-desacatos-5400040.pdf. Acceso en: 25 de agosto de 2019

UICN. Declaración Mundial de la Unión Internacional para la Conservación de la Naturaleza (UICN) acerca del Estado de Derecho en materia ambiental, 2016. Disponible en: https://www.iucn.org/sites/dev/files/content/documents/spanish_declaracion_mundial_de_la_ uicn_acerca_del_estado_de_derecho_en_materia_ambiental_final.pdf. Acceso en: 29 de agosto de 2019.

WINTER, Gerd. Um fundamento e dois pilares: o conceito de desenvolvimento sustentável 20 após o Relatório Brundtland. In: MACHADO, Paulo Affonso Leme; KISHI, Sandra Akemi Shimada (org.). Desenvolvimento sustentável, OGM e responsabilidade civil na União Europeia. Tradução de Carol Manzoli Palma. Campinas: Millennium, 2009.

Recebido em: 17 set. 2019.

Aceito em: 12 nov. 2019. 